\title{
Una investigación con docentes universitarios sobre el afrontamiento del estrés laboral y el síndrome del "quemado"
}

Eloísa Guerrero Barona

Universidad de Extremadura

\section{INTRODUCCIÓN}

Con este artículo deseamos difundir el reciente estudio, que durante cinco años, hemos llevado a cabo en la Universidad de Extremadura (UEX) (España) sobre la incidencia del síndrome de burnout y del afrontamiento del estrés laboral en el profesorado universitario.

Burnout, es un término anglosajón cuya traducción más próxima y coloquial es "estar quemado", desgastado, exhausto y perder la ilusión por el trabajo. Si bien, la literatura sobre el tema es cada día más voluminosa, uno de los inconvenientes para abordar este estudio, ha sido la inexistencia de un marco teórico estructurado, ya que la mayoría de los estudios se han centrado en áreas muy concretas, tales como el estudio de factores organizacionales, predisposicionales, sociodemográficos, acontecimientos vitales y familiares estresantes, o sobre aspectos relacionados con la salud.

Iniciamos el trabajo revisando la literatura existente acerca de la problemática de los docentes, el desgaste profesional que ocasiona la docencia y su incidencia, el afrontamiento del estrés y los modelos etiológicos que lo explican.

En primer lugar, analizamos la interdisciplinaridad de la problemática docente que comprende las diferentes disciplinas desde las que se ha abordado: Ciencias de la Educación, Sociología y Psicología. Dentro de esta última, profundizamos en los enfoques procedentes de la Psicología dinámica, de la Psicología de la salud y de la Psicología organizacional, siendo ésta última la que, en nuestra opinión mejor sistematiza el estrés laboral u ocupacional.

En segundo lugar abordamos el desgaste psíquico laboral o síndrome de burnout. Llevamos a cabo la delimitación conceptual del término, comparando estrés ansiedad y depresión. También se trataron las relaciones y críticas terminológicas del término, las perspectivas desde las que se ha estudiado, la sintomatología característica, el proceso de su desarrollo, y por último, los distintos instrumentos empleados para su medición y evaluación (Guerrero, 1998).

Aunque no existe una definición unánimemente aceptada sobre burnout, sí parece haber consenso en que se trata de una respuesta al estrés laboral crónico, una experiencia subjetiva que engloba sentimientos y actitudes con implicaciones nocivas para la persona y la organización. Gil-Monte y Peiró (1997) han afirmado que el síndrome del quemado puede

estudiarse desde dos perspectivas, clínica y psicosocial. La perspectiva clínica asume el burnout como un estado (concepción estática) al que llega el sujeto como consecuencia del 
estrés laboral, y la psicosocial, lo define como un proceso con una serie de etapas que se generan por interacción de las características personales y del entorno laboral.

Desde una perspectiva clínica, Freudenberger (1974), empleó por vez primera el término burnout para describir un conjunto de síntomas físicos sufridos por personal sanitario como resultado de las condiciones de trabajo. Según este autor, es típico de las profesiones de servicios de ayuda y se caracteriza por un estado de agotamiento como consecuencia de trabajar intensamente, sin tomar en consideración las propias necesidades. Este enfoque defiende que burnout aparece más frecuentemente, en los profesionales más comprometidos, en los que trabajan más intensamente ante la presión y demandas de su trabajo, poniendo en segundo término sus intereses. Se trata de una relación inadecuada entre profesionales, excesivamente celosos en su trabajo y clientes excesivamente necesitados, una respuesta del profesional asistencial al realizar un sobreesfuerzo.

En esta misma línea, Fischer (1983) consideró el burnout como un estado resultante del trauma narcisista que conllevaba una disminución en la autoestima de los sujetos, mientras que Pines y Aronson (1988), lo conceptualizan como un estado en el que se combinan fatiga emocional, física y mental, sentimientos de impotencia e inutilidad y baja autoestima. Iba acompañado de un conjunto de síntomas que incluía vacío físico, sentimientos de desamparo y desesperanza, desilusión y desarrollo de un autoconcepto y una actitud negativa hacia el trabajo y hacia la vida misma. En su forma más extrema, el burnout representa un punto de ruptura más allá del cual la capacidad de enfrentarse con el ambiente resulta severamente disminuida y es especialmente duro para personas entusiastas e idealistas.

Esta imagen del profesional como héroe trágico, víctima de su propio celo e idealismo, que paga un elevado precio por su alto rendimiento, fue la primera aproximación a este fenómeno, pero no se ajusta al modelo que actualmente se acepta (Manassero y col., 1994).

Desde una perspectiva psicosocial, la mayoría de sus adeptos, aceptan hoy la definición de burnout elaborada por Maslach y Jackson (1986), quienes lo consideran como una respuesta, principalmente emocional, situando los factores laborales y los organizacionales como condicionantes y antecedentes.

Los estudios de Maslach y Jackson (1981, 1985 y 1986) defienden que burnout es un síndrome tridimensional que se desarrolla en aquellos profesionales cuyo objeto de trabajo son personas (usuarios) y añaden tres dimensiones características. La primera es el Agotamiento emocional que se define como cansancio y fatiga que puede manifestarse física, psíquicamente o como una combinación de ambos. Es la sensación de no poder más de sí mismo a los demás. Despersonalización es la segunda dimensión y se entiende como el desarrollo de sentimientos, actitudes, y respuestas negativas, distantes y frías hacia otras personas, especialmente hacia los beneficiarios del propio trabajo. Se acompaña de un incremento en la irritabilidad y una pérdida de motivación hacia el mismo. El profesional trata de distanciarse no sólo de las personas destinatarias de su trabajo sino también de los miembros del equipo con los que trabaja, mostrándose cínico, irritable, irónico e incluso utilizando a veces etiquetas despectivas para aludir a los usuarios y tratando de hacerles culpables de sus frustraciones y 
descenso del rendimiento laboral. Junto a estas dos dimensiones aparece una tercera, consistente en un sentimiento de bajo Logro o realización profesional y/o personal y que surge cuando se verifica que las demandas que se le hacen, exceden su capacidad para atenderlas de forma competente. Supone respuestas negativas hacia uno mismo y hacia su trabajo, evitación de las relaciones personales y profesionales, bajo rendimiento laboral, incapacidad para soportar la presión y una baja autoestima. La falta de logro personal en el trabajo se caracteriza por una dolorosa desilusión y fracaso en dar sentido personal al trabajo. Se experimentan sentimientos de fracaso personal (falta de competencia, de esfuerzo o conocimientos), carencias de expectativas y horizontes en el trabajo, y una insatisfacción generalizada. Como consecuencia: la impuntualidad, la abundancia de interrupciones, la evitación del trabajo, el absentismo y el abandono de la profesión, son síntomas habituales y típicos de esta patología laboral. En opinión de Alvarez y Fernández (1991), el bajo logro puede, también, estar encubierto por una sensación paradójica de omnipotencia.

En conclusión, el enfoque psicosocial asume que burnout es un síndrome de Agotamiento emocional, Despersonalización y bajo Logro o realización personal en el trabajo.

Si bien, la mayoría de las investigaciones actuales aceptan la perspectiva psicosocial, algunos autores discrepan de los supuestos planteados por Maslach y Jackson (1981), entre los que se encuentran Price y Murphy (1984), Farber (1985, 1991), Golembiewski y col. (1991), Leiter y Maslach (1988) y Gil-Monte y Peiró (1997). Por ejemplo, Golembiewski y col. (1983, 1986) aseguran que el burnout afecta a todo tipo de profesiones y no sólo a las organizaciones de ayuda, y de hecho, gran parte de sus investigaciones emplean como muestra a directivos, vendedores, etc.

Gil-Monte y Peiró (1997) han constatado que el síndrome de quemarse en el trabajo queda establecido como una respuesta al estrés laboral crónico integrado por actitudes y sentimientos negativos hacia las personas con las que se trabaja y hacia el propio rol profesional, así como por una vivencia de encontrarse emocionalmente agotado. Esta respuesta se da, frecuentemente, en las organizaciones de servicios, aunque no está restringida a ellas.

De lo que no parece haber dudas es de que el síndrome de burnout comprende una serie de alteraciones físicas, comportamentales y emocionales que tienen su origen en factores individuales, laborales y sociales. En cuanto a los síntomas, diversos autores (Maslach y Pines, 1977; Cherniss, 1980 y Maslach, 1982) revelan que se pueden agrupar en cuatro áreas sintomatológicas. La primera abarca síntomas psicosomáticos y destacan: dolores de cabeza, fatiga crónica, úlceras o desórdenes gastrointestinales, dolores musculares en la espalda y cuello, hipertensión y en las mujeres pérdidas de ciclos menstruales. La segunda engloba síntomas conductuales tales como: absentismo laboral, conducta violenta, abuso de drogas, incapacidad de relajarse, etc.

El distanciamiento afectivo que el profesional manifiesta a las personas a las que atiende, la impaciencia, los deseos de abandonar el trabajo y la irritabilidad, forman parte de las manifestaciones emocionales que conforman el tercer grupo sintomatológico. Es también frecuente, la dificultad para concentrarse debido a la ansiedad experimentada, produciéndose así un descenso del rendimiento laboral, al mismo tiempo, le surgen dudas acerca de su propia 
competencia profesional, con el consiguiente descenso en su autoestima. Por último, los autores señalan los síntomas defensivos que aluden a la negación emocional. Se trata de un mecanismo que utiliza el profesional para poder aceptar sus sentimientos, negando las emociones anteriormente descritas cuyas formas más habituales son: negación de las emociones, ironía, atención selectiva y el desplazamiento de sentimientos hacia otras situaciones o cosas. También pueden utilizar para defenderse la intelectualización o la atención parcial hacia lo que le resulta menos desagradable (Alvarez y Fernández, 1991 y PSISA, 1993 ).

Cherniss (1992) ha realizado un análisis cualitativo y longitudinal de la evolución de algunos rasgos ligados al burnout (satisfacción ocupacional, motivación profesional, sentimiento/percepción de los clientes y separación/angustia emocional) en veinticuatro profesionales (sanitarios, docentes y abogados), controlando las variables estabilidad profesional, satisfacción profesional, percepción u opinión de los receptores de los servicios y flexibilidad en la intervención profesional, desde su iniciación en la profesión hasta doce años después. Los resultados de esta investigación revelan que los sujetos que cambiaron de carrera alguna vez durante los diez años siguientes de finalizarla, mostraron puntuaciones significativamente más bajas en burnout que los que no lo hicieron. Al principio de la carrera, no se encontraron diferencias significativas en burnout ni en la satisfacción profesional ni en las actitudes hacia los clientes. Los sujetos que puntuaron alto en burnout al finalizar su primer año de prácticas eran también más flexibles con sus clientes diez años más tarde y experimentaban mayor estabilidad en su profesión. Estos resultados indican que, o bien los individuos que experimentaron menos burnout al principio era psicológicamente más resistentes y estaban menos predispuestos a riesgos, o bien, eran más selectivos en la elección de su carrera. Por otro lado, los profesionales que experimentaron niveles elevados de burnout al principio de la carrera, eran personas que tendían a evitar cambios en su trabajo para prevenir posibles experiencias negativas. Una interpretación alternativa podría ser que la tensión experimentada al principio proporcionaba mayor seguridad y confianza posteriormente.

Después de haber señalado, todo el conjunto de manifestaciones características de esta patología laboral, se justifica que en la literatura especializada se hable, indiferenciadamente, de burnout, de síndrome de burnout, de desgaste psíquico, o más coloquialmente, de quemarse en el trabajo.

Los adeptos de la perspectiva psicosocial afirman que el síndrome hay que entenderlo como un proceso que se desarrolla secuencialmente, en lo referente a la aparición de sus rasgos y sus síntomas globales. En cambio, algunos autores van a discrepar en el síntoma que se presenta en primer lugar, la secuencia del proceso, el protagonismo que conceden a cada uno de sus síntomas globales, en la explicación de los mecanismos explicativos y en las estrategias que el individuo puede emplear para manejarlo. De ahí que hayan surgido varios modelos procesuales que traten de explicar el desarrollo de este proceso. Los modelos etiológicos explicativos del síndrome, siguiendo la revisión de Gil Monte y Peiró (1997), ha quedado estructurado en tres grandes teorías: sociocognitiva, teoría del intercambio social y la teoría organizacional que a su vez engloban los modelos de Spaniol y Caputo (1979); Harrison 
(1980; 1983); Cherniss (1980); Edelwich y Brodsky (1980); Goelmbiewski, Munzenrider y Carter (1983); Pines y Aronson (1988); Farber (1991); Starnam y Miller (1992); Cox, Kuk y Leiter (1993) y Winnubst (1993).

En lo referente al afrontamiento del estrés docente, hemos constatado que la literatura revisada abarca varias aproximaciones teóricas y diferentes clasificaciones sobre estrategias de afrontamiento del estrés. Nosotros contemplamos también las diferentes medidas para su evaluación e incluimos, un último aspecto que relaciona estrés, afrontamiento y repercusiones sobre la salud (Guerrero, 1998).

En el último apartado de esta primera parte, correspondiente al marco teórico, nos centramos, pormenorizadamente en la incidencia del síndrome en la profesión docente, que engloba el análisis de las variables influyentes (sociodemográficas, laborales y motivacionales), una clasificación tipológica de profesores "quemados" y dedicamos, finalmente, un espacio al profesorado universitario, objetivo prioritario de nuestro estudio. Analizamos la institución universitaria, el profesorado universitario y sus funciones, la polémica sobre la dualidad docencia e investigación, el factor humano en la realización personal y profesional, y por último, los centros y departamentos como unidades de estudio y reflexión (Guerrero, 1998).

\section{MATERIAL Y MÉTODO}

La segunda parte de la investigación corresponde al estudio empírico. El aspecto metodológico comprende los objetivos, las hipótesis, el procedimiento, la obtención de la muestra, los instrumentos de evaluación y el tratamiento estadístico efectuado.

Principalmente, nos propusimos los siguientes objetivos operativos:

- Estudiar si el profesorado de la Universidad de Extremadura padece síndrome de Burnout y el grado del mismo (alto, medio y bajo).

- Comparar el grado de Burnout del profesorado universitario con el de otros niveles educativos (primaria, secundaria y bachillerato).

- Examinar qué niveles de Burnout (extremo, bastante, medio, poco y nada) presentan los sujetos de la muestra.

- Verificar si el síndrome de Burnout es un constructo multidimensional (Maslach y Jackson, 1986) y si las tres dimensiones que lo conforman son independientes entre sí.

- Realizar la estadística descriptiva de cada una de las dimensiones del síndrome y detectar si los resultados discrepan de los obtenidos en otras investigaciones nacionales realizadas.

- Cotejar los promedios de Burnout en la muestra universitaria con los obtenidos en otros profesionales asistenciales.

- Analizar los 22 ítems que conforman el Inventario de Maslach (Maslach y Jackson, 1986).

- Estudiar las estrategias de afrontamiento que emplea el profesorado de la UEX en situaciones de estrés laboral. 
- Analizar los 60 ítems que conforman la Escala de evaluación del técnicas de afrontamiento Carver et al. (1989).

HIPÓTESIS

Partimos de las siguientes hipótesis de trabajo:

- El profesorado universitario que mayor Agotamiento emocional sufre presenta también sentimientos de Despersonalización más frecuentemente y de modo significativo, es decir, la dimensión Despersonalización es directamente proporcional a la dimensión Agotamiento emocional.

- Agotamiento emocional y Despersonalización son inversamente proporcional a Logro y realización personal.

- El síndrome de Burnout está significativamente relacionado con los modos de afrontar situaciones estresantes laborales.

- Los modos de afrontamiento del estrés diferencian significativamente a los sujetos de la muestra en función de los grados (alto, medio y bajo) de Burnout que pudieran padecer. Por tanto, existen diferencias significativas entre los grados de Burnout y modos específicos de afrontar el estrés.

- Los factores sociodemográficos, laborales así como los motivacionales entre sí y, los relacionados con la salud, pudieran influir en la aparición del síndrome y en los diferentes niveles (nada, poco, medio, bastante y extremo) de Burnout, y los modos de afrontar el estrés.

- El síndrome de Burnout pudiera predecirse a partir de factores sociodemográficos, laborales y motivacionales, es decir, los factores sociodemográficos, laborales y motivacionales son buenos predictores de Burnout

- De todas las variables predictoras que se analizan, los modos de afrontamiento del estrés son excelentes predictores del síndrome de Burnout en las tres dimensiones y son comparativamente, quienes mejor lo predicen.

- Los diferentes niveles de Burnout (extremo, bastante, medio, poco, nada) están asociados a factores sociodemográficos, laborales, motivacionales y modos de afrontamiento.

- Los diferentes grados de Burnout (alto, medio, bajo) están asociados a factores sociodemográficos, laborales, motivacionales y/o modos de afrontamiento.

- El absentismo laboral docente puede inferirse a partir de factores sociodemográficos, laborales, motivacionales y modos de afrontamiento.

- Los modos de afrontamiento del estrés pueden predecirse a partir de factores sociodemográficos, laborales, motivacionales.

- Ciertas variables sociodemográficas guardan relación con estrategias de afrontamiento específicas.

\section{MUESTRA Y PROCEDIMIENTO}

El procedimiento para la obtención de la muestra consistió en enviar a los profesores de la Universidad de Extremadura, a través de correo interno, los instrumentos de evaluación que se 
describen en el siguiente apartado. El proceso de recogida de cuestionarios se cerró a principios del mes de septiembre del curso 96-97.

Después de invalidar 18 cuestionarios, por estar incorrectamente cumplimentados, la muestra definitiva quedó formada por 257 profesores pertenecientes a los dos semidistritos (Cáceres y Badajoz), obteniéndose un promedio de participación del 26,20\%.

\section{INSTRUMENTOS DE EVALUACIÓN}

Los instrumentos de evaluación que empleamos constan de una batería de cuestionarios que engloban: un cuestionario sociodemográfico, laboral y motivacional de elaboración propia, el Inventario de Burnout de Maslach o M.B.I.(1986), que se emplea para medir el síndrome de Burnout y por último, la Escala de evaluación de técnicas de afrontamiento de Carver et al. o C.O.P.E. (1989) que valora los distintos modos de afrontamiento del estrés.

El cuestionario sociodemográfico, laboral y motivacional engloba aspectos biológicos y sociales (sexo, edad, estado civil, paternidad y $n^{\circ}$ de hijos); laborales (semidistritos, áreas de conocimiento, categorías laborales docente, años de experiencia docente) y otros de carácter más cognitivos y motivacionales (absentismo, $n^{\circ}$ de días de BLT, causas de BLT, factores de satisfacción en la docencia o alicientes y finalmente, factores de insatisfacción en la docencia o inconvenientes). A través de este cuestionario examinamos los factores que pudieran ser antecedentes o moduladores en la aparición del síndrome de Burnout.

El Inventario de Maslach ó M.B.I. (1986) lo empleamos con el fin de evaluar las tres dimensiones del síndrome: Agotamiento emocional, Despersonalización y Logro personal.

El último instrumento que empleamos es la Escala de Carver y col. ó C.O.P.E. (1989). Mide el afrontamiento del estrés en sus aspectos conductuales y cognitivos. Como resultado de su cumplimentación, se obtienen los quince modos de afrontamiento: Afrontamiento Activo, Planificación, Búsqueda de Apoyo Social Instrumental, Búsqueda de Apoyo Social Emocional, Supresión de Actividades Distractoras, Religión, Reinterpretación Positiva, Refrenar el Afrontamiento, Aceptación, Desahogarse, Negación, Desconexión Mental, Desconexión Conductual, Consumo de Droga y Humor.

TRATAMIENTO ESTADÍSTICO

En cuanto al tratamiento estadístico, procedimos a realizar estadísticas descriptiva y de contraste entre las variables sociodemográficas, laborales, motivacionales y las tres dimensiones del M.B.I y las quince subescalas de COPE .

El tratamiento de los datos se efectúa a un nivel de confianza del $95 \%$ y con un margen de error del $5 \%$. Las variables categóricas aparecen en tablas de contingencia, distribuciones de frecuencias y se expresan gráficamente. Las cuantitativas son tratadas mediante estadística descriptiva empleando los estadísticos media, desviación típica, error estándar, coeficientes de variación y percentiles.

El análisis inferencial se efectúa en función de la naturaleza de las variables a tratar y de los grupos de contrastes, y para ello utilizamos las pruebas $T$ de Student, Ji- cuadrado y análisis de varianza o ANOVA. 
Para comparar la potencia predictiva de las distintas variables predictoras respecto de los criterios, la estadística se completa con un análisis de regresión múltiple y con la técnica ‘stepwise' o regresión por pasos.

\section{RESULTADOS Y CONCLUSIONES}

El análisis de datos que hemos efectuado consta de los análisis descriptivo, inferencial, pormenorizado y de regresión.

De la aplicación de la estadística descriptiva se derivan el perfil sociodemográfico y laboral de la población docente de la UEX, el análisis comparativo de la población y la muestra, el perfil sociodemográfico, laboral y motivacional de la muestra, así como la descripción muestral en el MBI y COPE.

En el análisis descriptivo muestral incluimos la descripción de las características laborales, sociodemográficas y motivacionales, también los análisis descriptivos del M.B.I y del C.O.P.E.

A través del análisis inferencial hemos contrastado MBI, COPE y las variables sociodemográficas, laborales y motivacionales. Mediante el análisis pormenorizado comparamos, por un lado, las tres dimensiones del MBI entre sí y por el otro, contrastamos los diferentes Grados de Burnout y los quince modos de afrontamiento.

Finalmente, empleamos como criterios en el análisis de regresión múltiple y por pasos, las variables: Burnout, niveles y grados de Burnout, absentismo y modos de afrontamiento.

- En relación a los objetivos y a nivel descriptivo hemos obtenido el siguiente perfil sociodemográfico y laboral de la población docente universitaria:

Durante el curso 95-96 en la Universidad de Extremadura predomina el género masculino $(70 \%)$, cuyas edades están comprendidas entre los 35-45 años (43\%), casados-as $(70 \%)$ y aproximadamente la mitad de ellos tienen hijos. Pertenecen al semidistrito de Cáceres el $45,5 \%$ de la población docente y el resto al de Badajoz. El $72,30 \%$ son profesores de Facultad y el resto de Escuelas Universitarias.

Aproximadamente, el $55 \%$ del profesorado es numerario en las distintas categorías laborales. Destaca la categoría docente de profesor Asociado $(41 \%)$ y los centros que mayor número de ellos albergan son las Facultades de Medicina y Derecho (67\% y $44 \%$ respectivamente). En lo que respecta al grado de doctor poseen el título, alrededor del $50 \%$ del profesorado de la UEX.

De los cuarenta departamentos existentes hay dos que cuentan con la mayor plantilla docente: el de Patología y Clínicas Humanas (7,8\%) y el de Economía Aplicada a Organizaciones Empresariales (5,11\%). Los departamentos que cuentan con menos recursos humanos, no llegando a superar el 1\%, son los de Geografía y Ordenación Territorial, Química Inorgánica y Química Física.

- También del análisis de datos extraemos el perfil sociodemográfico, laboral y motivacional de la muestra y los aspectos más característicos son: 
La participación del género masculino duplica (69\%) al femenino y, aproximadamente, el $85 \%$ de la participación tienen edades inferiores a 45 años.

Más del $70 \%$ están casados-as y tienen descendencia un $64,5 \%$. No se observan apenas diferencias en los porcentajes de participación en los dos semidistritos. Sí, en cambio, se constatan diferencias en la participación por centros, siendo las Facultades de Ciencias $(25 \%)$ y Veterinaria $(15,5 \%)$ los más colaboradores. Es escasa la participación del profesorado en las Facultades de Medicina (1,95\%) y de Derecho (1,56\%).

Según el Área de conocimiento al que pertenecen, destacamos que la mayor proporción de participación corresponde al profesorado del área científica (36\%) y la menor a los del área social (12,5\%). Predominan en general las categorías docentes de profesor Asociado (34\%) y Titulares Universidad-Catedráticos de Escuelas Universitarias (31\%).

El $46 \%$ posee una experiencia media de ejercicio profesional de 5 a 15 años y destaca la escasa colaboración del profesorado con menos de cinco.

Referente al absentismo, la mitad del profesorado se ausentó en alguna ocasión por razones de salud, y en cuanto al Número de días de B.L.T., predominan las bajas de 2 a 4 días de duración (80\%). El $75 \%$ de las ausencias por enfermedad se deben a causas "menores" (resfriados, malestar general, dolor de cabeza, alteraciones intestinales, mareos, etc.) y si bien en profesoras la proporción de B.L.T. por problemas psiquiátricos es mínima $(0,84 \%)$, en el género masculino no se constatan.

Respecto a las opiniones acerca de las principales fuentes de satisfacción que encuentran en la profesión docente universitaria, casi la mitad del profesorado atribuyen a la "docencia" el principal Aliciente. Es escaso, por el contrario, el valor que atribuyen a las "relaciones" humanas e interpersonales que se establecen en el contexto universitario $(6,61 \%)$.

El 33\% de la muestra encuentra en la "masificación" del alumnado el principal Inconveniente en la profesión universitaria. Como fuentes de insatisfacción le siguen el bajo sueldo $(17 \%)$, la falta de base del alumnado $(16 \%)$ y las relaciones interpersonales $(13,6 \%)$.

- Los resultados muestrales en el Inventario de Maslach (1986) son los siguientes:

Atendiendo a una interpretación globalizada del Grado de Burnout (alto, medio, bajo) las puntuaciones que presentan los docentes de la UEX se sitúan en un grado medio. Al comparar los resultados con muestras de profesores americanos y españoles de otros niveles educativos, los resultados son similares.

En la Tabla 1 resumimos la estadística descriptiva del MBI (1986): 


\begin{tabular}{|c|c|c|c|c|c|c|c|c|c|}
\cline { 2 - 10 } \multicolumn{1}{c|}{} & Media & Md & Sx & Se & Cf. Var. & C10 & C90 & Cf. As. & Cf. Cur. \\
\hline Agotamiento E. & 9,80 & $\begin{array}{c}8 y \\
12\end{array}$ & 6,02 & 0,37 & 61,37 & 3 & 18 & 0,81 & 0,72 \\
& & & & & & & & \\
\hline Despersonalización & 3,47 & 2 & 2,98 & 0,18 & 86,02 & 0 & 7 & 1,28 & 2,15 \\
\hline Logro Personal & 20,66 & 23 & 6,07 & 0,37 & 29,39 & 13 & 29 & $-0,14$ & $-0,71$ \\
\hline
\end{tabular}

Tabla 1. Estadística descriptiva del Inventario de Maslach (Maslach y Jackson, 1986)

$\mathrm{Md}=\operatorname{moda}$

Sx = desviación típica

Se $=$ error típico

Cf. As = coeficiente de Asimetría de Fisher

Cf. Cur. = coeficiente de curtosis

Atendiendo a cada una de las dimensiones, los valores medios de Burnout en cada una de ellas son: 9,80 para Agotamiento emocional, 3,47 para Despersonalización y 20,60 para Logro personal. El profesorado de la muestra está más agotado emocionalmente que despersonalizado.

Gráficamente, se puede observar el perfil que los profesores de la UEX presentan en el síndrome de Burnout (Gráfico1)

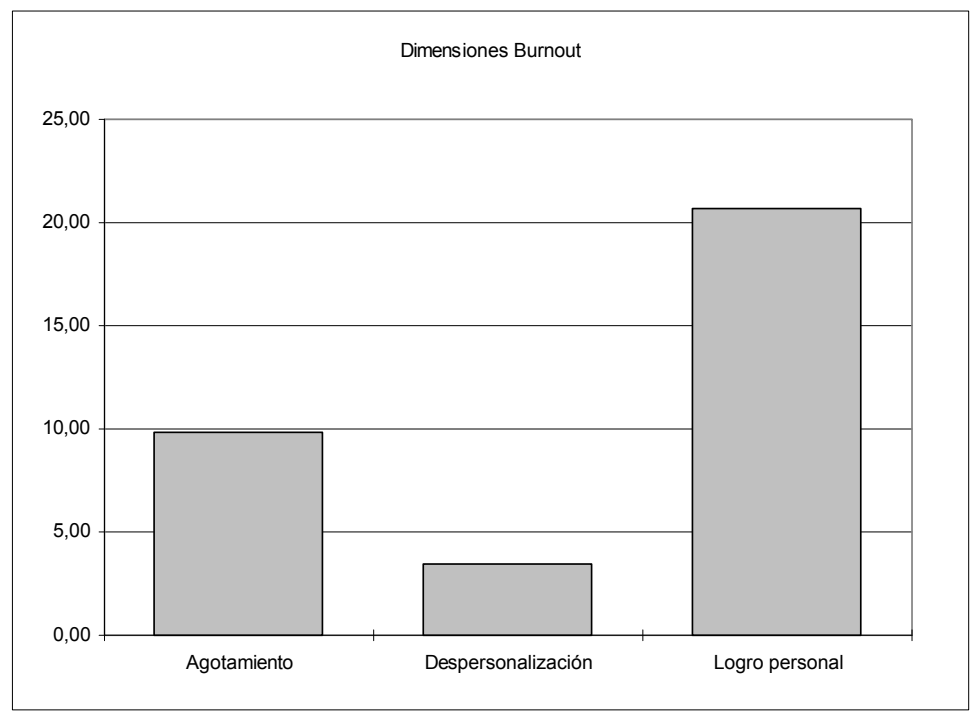

\section{Gráfico 1. Promedios de Burnout. Análisis tridimensional}

En cuanto al análisis por patrones, y habiéndose categorizado en cinco niveles de Burnout (nada, poco, medio, bastante y extremo), constatamos que un $23 \%$ del profesorado de la muestra se sitúa en el nivel máximo de Burnout y un $21 \%$ en el mínimo. En general, los resultados indican que el $41 \%$ aproximadamente del profesorado de la muestra está casi exento de Burnout, el $42 \%$ presentan niveles preocupantes ya que superan la media y un $17 \%$ presenta un grado moderado. 


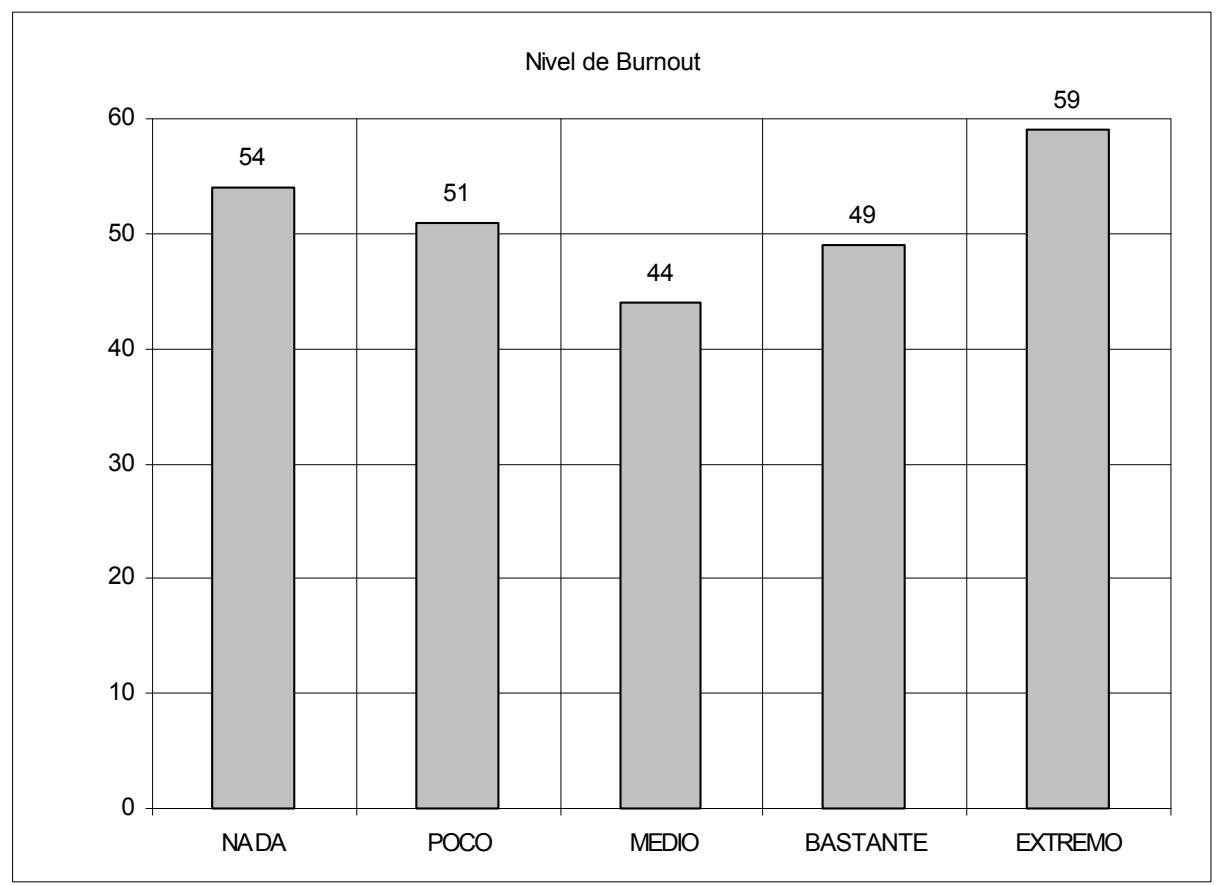

Gráfico 2. Distribución de frecuencia de niveles de burnout. Análisis por patrones

Del análisis de correlación que realizamos tomando las tres escalas del $\mathrm{MBI}$, se concluye que, si bien las tres dimensiones que definen el síndrome son independientes entre sí, presentan una relación lineal entre ellas, con lo cual nos encontramos ante un constructo multidimensional. Existe un $35 \%$ de varianza asociada y explicada por las dimensiones Despersonalización y Agotamiento emocional.

Al comparar el Burnout que presentan los docentes de diferentes niveles educativos con otras profesiones asistenciales, se verifica que la variable Logro personal es mayor en otros colectivo asistenciales que en los docentes de universidad y que éstos últimos presentan un Logro personal menor cuando se les compara con niveles educativos inferiores.

Aparecen diferencias en las frecuencias de algunos ítems que componen el M.B.I. (1986). Los valores medios más altos acontecen, por orden decreciente, en los items 4, 18, 17 , 19 y 7 , todos pertenecientes a la dimensión Logro personal. Por el contrario, los valores medios más bajos se obtienen en los ítems 15, 5, 11, 13 y 22. Excepto el ítem 13 que pertenece a la dimensión Agotamiento emocional, el resto corresponde a la dimensión Despersonalización.

- Los resultados muestrales en la Escala COPE (1989) ponen de manifiesto que las cinco estrategias de afrontamiento que más frecuentemente emplean los profesores de la UEX son: Planificación, Reinterpretación Positiva, Afrontamiento Activo, Búsqueda de Apoyo Instrumental y Búsqueda de Apoyo Social, estrategias centradas en el problema y en la búsqueda de soluciones. Así mismo, las menos utilizadas son: Consumo de Drogas, Negación, Desconexión Conductual, Desconexión Mental y Religión. Éstas últimas están relacionadas con estrategias evasivas, de resignación y evitación del afrontamiento. 


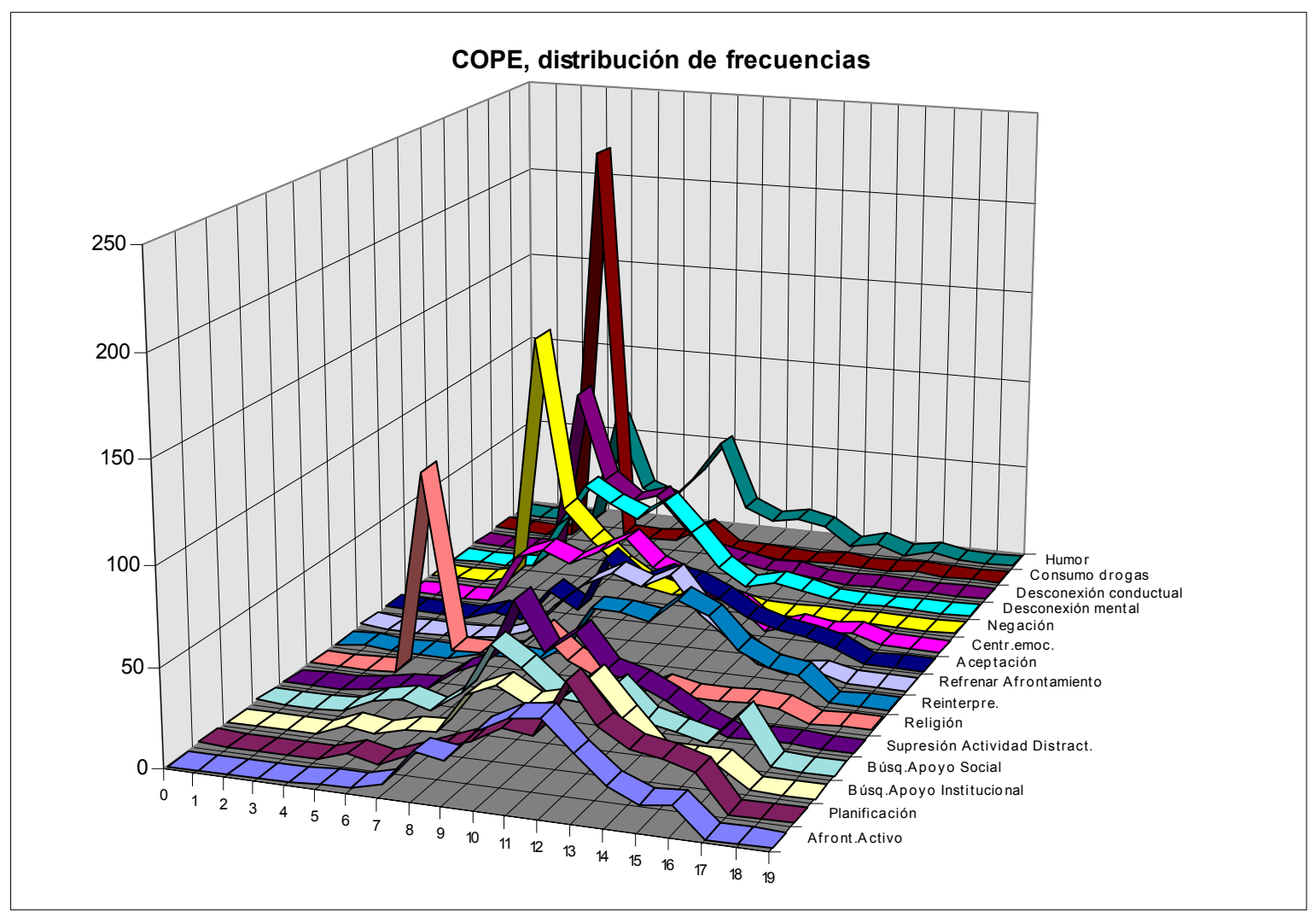

\section{Gráfico 4. Distribución de frecuencia de respuestas en COPE}

En el análisis de los ítems que conforman la Escala COPE (1989) se observa que presentan medias superiores los ítems $59,1,44,39$ y 5 y los promedios inferiores ocurren en los ítems 53, 26, 35, 12 y 27.

Como resultado del análisis de correlación que llevamos a cabo con los quince modos de afrontamiento del estrés, observamos como las estrategias Planificación-Afrontamiento Activo $(\mathrm{Rxy}=0,06)$ y Planificación-Reinterpretación Positiva $(\mathrm{R} x \mathrm{y}=0,05)$ están altamente correlacionadas, coincidiendo con las que más frecuentemente emplean el profesorado de la muestra. Lo mismo ocurre con las estrategias Desconexión Conductual-Negación (Rxy=0,05).

- En relación a las HIPÓTESIS Y PRONÓSTICOS hemos extraído múltiples conclusiones. Debido a su extensión, detallamos sólo algunas de ellas:

- De todos los factores sociodemográficos estudiados, Estado civil $(F=3,29 ; p=0,0211)$ y Paternidad $(t=-2,14 ; p=0,0328)$ son variables sensibles al síndrome de Burnout $y$ al modo de afrontar el estrés.

- Quemarse por el trabajo está significativamente relacionado con el modo de afrontamiento del estrés $(F=4,726, p=0,0001 ; F=3,635, p=0,0001 ; F=4,402 ; p=0,0005)$. 
- El profesorado de la UEX que mayor grado de Agotamiento Emocional y Despersonalización presenta, emplea como estrategia para manejar situaciones labores estresantes Desahogarse $(p=0,0001)$, estrategia centrada en las emociones y no en el problema.

- Hallamos diferencias, estadísticamente significativas, cuando contrastamos los dos Semidistritos y las variables Logro personal $(t=-2,49, p=0,0131)$, las estrategias de afrontamiento Refrenar el Afrontamiento $(F=3,91 ; p=0,0488)$ y Desconexión Conductual ( $F=$ 4,02; $\mathrm{p}=0,0459)$ y la asociación Áreas de conocimiento e Inconvenientes de la profesión ( $\mathrm{F}=$ 4,22; $p=0,004)$. Están afectadas las Áreas: "biomédica" y "científica" y los factores: "masificación" y "relaciones".

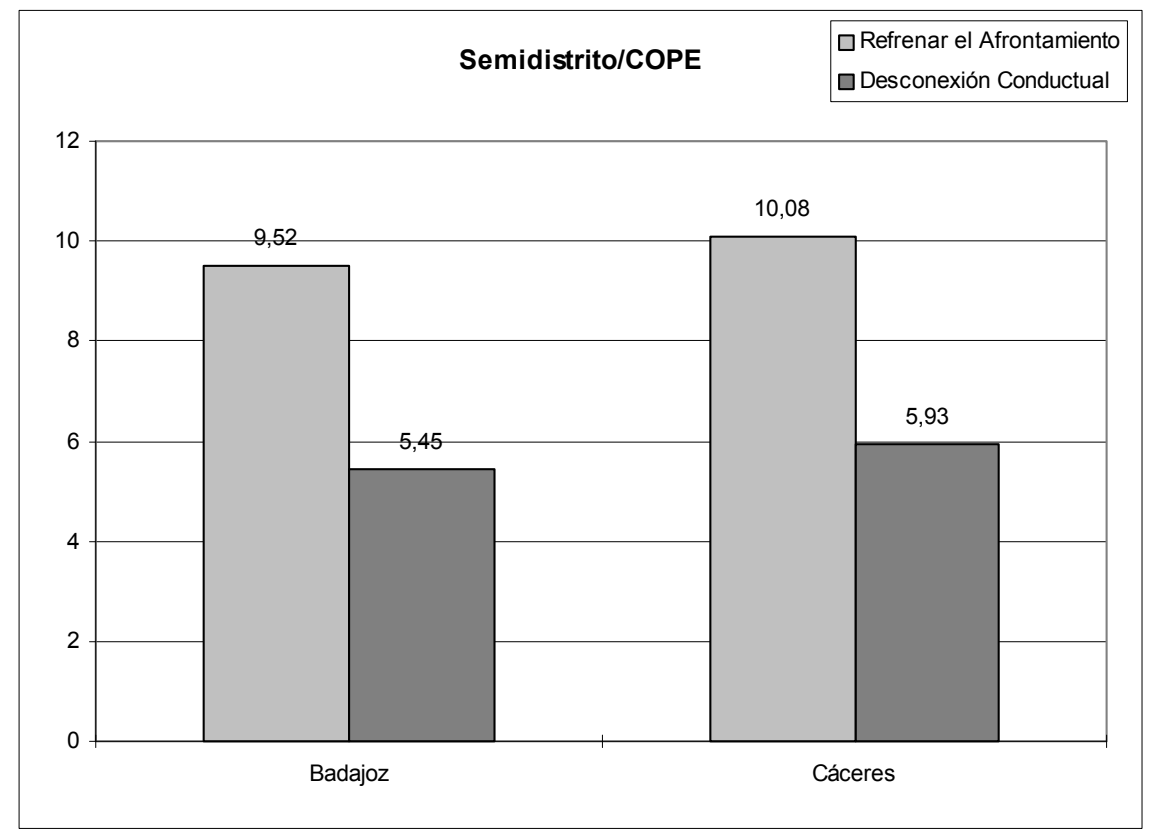

Gráfico 5. Valores medios Semidistritos/ Modos de afrontamiento

- Respecto a las dimensiones de Burnout y a su posible relación con Áreas de conocimiento, sólo aparece significación en Logro personal ( $F=2,317 ; p=0,0578)$, detectándose comparaciones significativas en la comparación Áreas Biomédica vs. Científica $(F=2,151)$, en donde el primer grupo alcanza valores superiores (Tabla 2) 


\begin{tabular}{|c|c|c|c|c|c|c|c|c|c|}
\hline \multicolumn{10}{|c|}{ M.B.I. } \\
\hline \multirow{3}{*}{$\begin{array}{c}\text { ÁREAS } \\
\text { conocimiento }\end{array}$} & \multicolumn{3}{|c|}{$\begin{array}{l}\text { Agotamiento } \\
\text { emocional }\end{array}$} & \multicolumn{3}{|c|}{ Despersonalización } & \multicolumn{3}{|c|}{ Logro personal } \\
\hline & \multicolumn{3}{|c|}{$P=0,6597 \quad F=0,60$} & \multicolumn{3}{|c|}{$P=1,309 \quad F=0,26$} & \multicolumn{3}{|c|}{${ }^{*} \mathrm{P}=\mathbf{0 , 0 5 7 8} \quad \mathrm{F}=2,31$} \\
\hline & Media & Sx & SE & Media & $S x$ & $\mathrm{SE}$ & Media & Sx & SE \\
\hline Biomédica & 10,48 & 7,46 & 1,11 & 3,28 & 3,69 & 0,55 & 22,77 & 6,32 & 0,94 \\
\hline Técnica & 10,29 & 5,82 & 0,84 & 4,35 & 3 & 0,43 & 20,83 & 6,12 & 0,88 \\
\hline Humanística & 9,75 & 5,82 & 0,93 & 3,23 & 2,79 & 0,44 & 20,56 & 6,16 & 0,98 \\
\hline Social & 8,5 & 5,44 & 0,96 & 3,18 & 2,83 & 0,50 & 20,96 & 6,38 & 1,12 \\
\hline Científica & 9,68 & 5,64 & 0,58 & 3,30 & 2,69 & 1,27 & 19,48 & 5,6 & 0,58 \\
\hline
\end{tabular}

Tabla 2. Resultados del ANOVA Áreas de conocimiento/Burnout

- Los profesores Ayudantes constituyen la categoría laboral docente más vulnerable al síndrome, ya que presentan un mayor Agotamiento emocional ( $F=2,06 ; p=0,0855)$, así como un descenso en Logro personal y frecuentes sentimientos de incompetencia $(F=1,976 ; p=$ 0,0987). Asimismo, el $91 \%$ de ellos está afectado por los máximos niveles de Burnout.

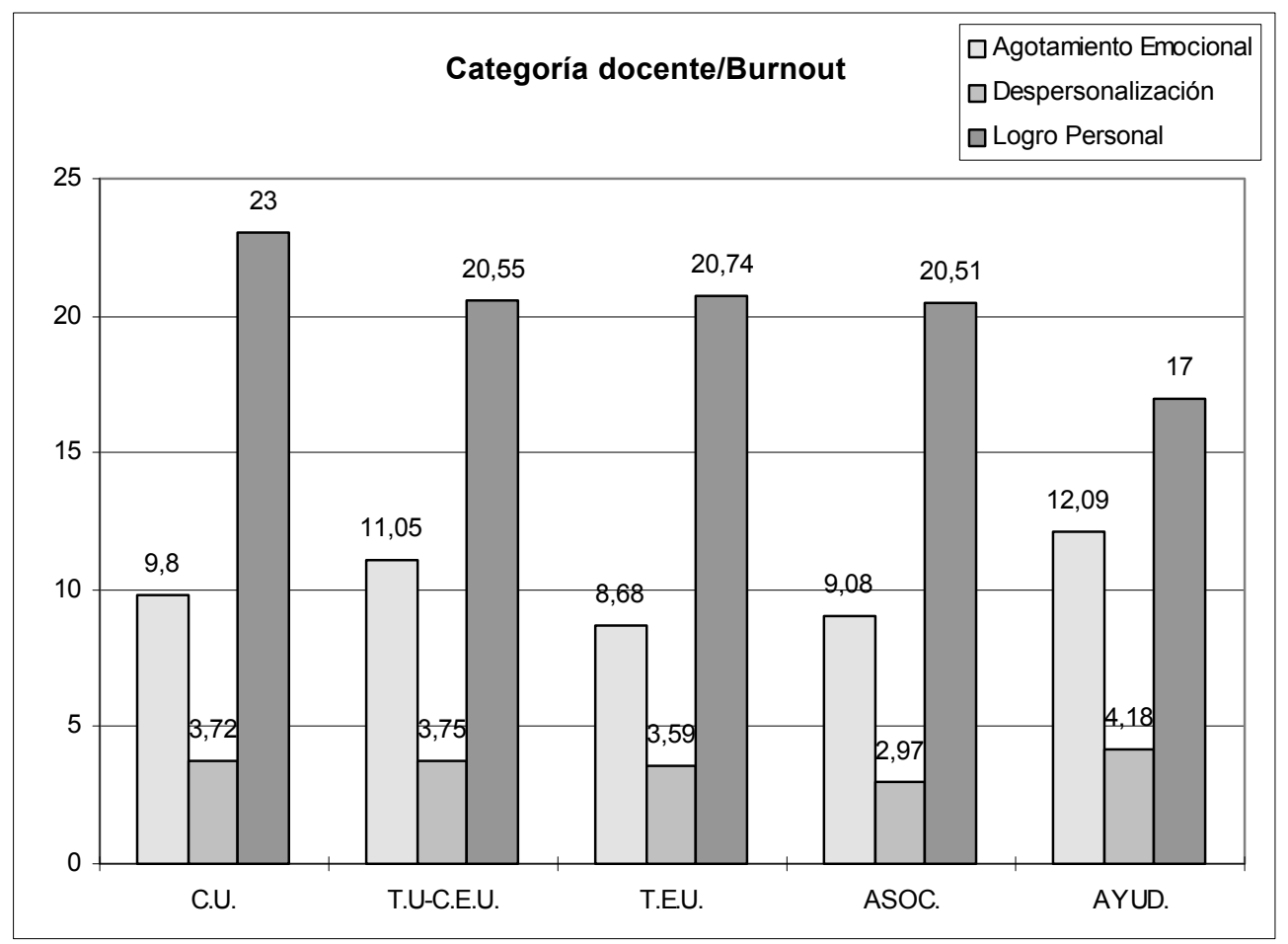

Gráfico 6. Valores medios Burnout/Categorías docentes

- También se diferencian significativamente de los Catedráticos de Universidad en el modo de afrontamiento del estrés (Tabla 3). Estos últimos se centran en el problema, utilizando específicamente Afrontamiento activo, Planificación y Reinterpretación positiva, al contrario que los Ayudantes que emplean Desahogarse, estrategia centradas en las emociones. 


\begin{tabular}{|c|c|c|c|c|c|c|c|c|c|c|c|c|c|c|c|}
\hline \multicolumn{16}{|c|}{ C.O.P.E. } \\
\hline Modos & \multicolumn{15}{|c|}{ CATEGORIAS DOCENTE } \\
\hline \multirow{4}{*}{$\begin{array}{c}\text { Afrontam } \\
\text { Activo }\end{array}$} & \multicolumn{15}{|c|}{$\mathrm{F}=3,424 \quad \cdot \mathrm{P}=\mathbf{0 , 0 9 5}$} \\
\hline & \multicolumn{3}{|c|}{ C.U } & \multicolumn{3}{|c|}{ T.U- C.E.U } & \multicolumn{3}{|c|}{ T.E.U } & \multicolumn{3}{|c|}{ ASOC. } & \multicolumn{3}{|c|}{ AYUD. } \\
\hline & $\begin{array}{c}\text { Medi } \\
\text { a }\end{array}$ & Sx & $\mathrm{Se}$ & $\begin{array}{c}\text { Medi } \\
\text { a } \\
\end{array}$ & Sx & Se & $\begin{array}{c}\text { Medi } \\
\text { a } \\
\end{array}$ & Sx & Se & $\begin{array}{c}\text { Medi } \\
\text { a }\end{array}$ & Sx & $\mathrm{Se}$ & $\begin{array}{c}\text { Medi } \\
\text { a }\end{array}$ & Sx & $\mathrm{Se}$ \\
\hline & $\begin{array}{c}12,5 \\
2\end{array}$ & $\begin{array}{c}2,5 \\
1\end{array}$ & $\begin{array}{c}0,5 \\
0\end{array}$ & $\begin{array}{c}11,1 \\
8\end{array}$ & $\begin{array}{c}1,8 \\
3\end{array}$ & $\begin{array}{c}0,2 \\
0\end{array}$ & $\begin{array}{c}11,7 \\
5\end{array}$ & $\begin{array}{c}2,1 \\
5\end{array}$ & 0,25 & $\begin{array}{c}10,9 \\
7\end{array}$ & $\begin{array}{c}2,4 \\
8\end{array}$ & $\begin{array}{c}0,2 \\
6\end{array}$ & $\begin{array}{c}12,3 \\
6\end{array}$ & $\begin{array}{c}2,2 \\
4\end{array}$ & $\begin{array}{c}0,6 \\
7\end{array}$ \\
\hline \multirow{4}{*}{ Planificac } & \multicolumn{15}{|c|}{$F=3,113 \quad{ }^{*} P=0,0159$} \\
\hline & \multicolumn{3}{|c|}{ C.U. } & \multicolumn{3}{|c|}{ T.U- C.E.U } & \multicolumn{3}{|c|}{ T.E.U } & \multicolumn{3}{|c|}{ ASOC. } & \multicolumn{3}{|c|}{ AYUD. } \\
\hline & $\begin{array}{c}\text { Medi } \\
\text { a }\end{array}$ & Sx & $\mathrm{Se}$ & $\begin{array}{c}\text { Medi } \\
\text { a }\end{array}$ & Sx & $\mathrm{Se}$ & $\begin{array}{c}\text { Medi } \\
\text { a }\end{array}$ & Sx & $\mathrm{Se}$ & $\begin{array}{c}\text { Medi } \\
\text { a }\end{array}$ & Sx & Se & $\begin{array}{c}\text { Medi } \\
\text { a }\end{array}$ & Sx & Se \\
\hline & 13 & $\begin{array}{c}2,6 \\
1 \\
\end{array}$ & $\begin{array}{c}0,8 \\
2\end{array}$ & $\begin{array}{c}11,4 \\
3 \\
\end{array}$ & $\begin{array}{c}2,3 \\
8 \\
\end{array}$ & $\begin{array}{c}0,2 \\
6\end{array}$ & $\begin{array}{c}11,9 \\
6 \\
\end{array}$ & $\begin{array}{c}2,2 \\
7 \\
\end{array}$ & 0,30 & $\begin{array}{c}11,4 \\
3 \\
\end{array}$ & $\begin{array}{c}2,3 \\
8 \\
\end{array}$ & $\begin{array}{c}0,2 \\
6\end{array}$ & $\begin{array}{c}13,0 \\
9 \\
\end{array}$ & $\begin{array}{c}2,4 \\
2 \\
\end{array}$ & $\begin{array}{c}0,7 \\
3\end{array}$ \\
\hline \multirow{4}{*}{$\begin{array}{c}\text { Reinterpr } \\
\text { et } \\
\text { Positiva }\end{array}$} & \multicolumn{15}{|c|}{$\mathrm{F}=2,665 \quad{ }^{*} \mathrm{P}=\mathbf{0 , 0 3 3}$} \\
\hline & \multicolumn{3}{|c|}{ C.U } & \multicolumn{3}{|c|}{ T.U- C.E.U } & \multicolumn{3}{|c|}{ T.E.U } & \multicolumn{3}{|c|}{ ASOC. } & \multicolumn{3}{|c|}{ AYUD. } \\
\hline & $\begin{array}{c}\text { Medi } \\
\text { a }\end{array}$ & Sx & Se & $\begin{array}{c}\text { Medi } \\
\text { a }\end{array}$ & Sx & Se & $\begin{array}{c}\text { Medi } \\
\text { a }\end{array}$ & Sx & Se & $\begin{array}{c}\text { Medi } \\
\text { a }\end{array}$ & Sx & $\mathrm{Se}$ & $\begin{array}{c}\text { Medi } \\
\text { a }\end{array}$ & Sx & $\mathrm{Se}$ \\
\hline & $\begin{array}{c}12,7 \\
6\end{array}$ & $\begin{array}{c}2,4 \\
0\end{array}$ & $\begin{array}{c}0,4 \\
8\end{array}$ & 11,1 & $\begin{array}{c}2,2 \\
3\end{array}$ & $\begin{array}{c}0,2 \\
4\end{array}$ & $\begin{array}{c}11,4 \\
2\end{array}$ & $\begin{array}{c}2,3 \\
2\end{array}$ & 0,31 & $\begin{array}{c}11,2 \\
9\end{array}$ & $\begin{array}{c}2,4 \\
5\end{array}$ & $\begin{array}{c}0,2 \\
6\end{array}$ & $\begin{array}{c}12,2 \\
7\end{array}$ & $\begin{array}{c}3,6 \\
6\end{array}$ & $\begin{array}{c}1,1 \\
0\end{array}$ \\
\hline \multirow{4}{*}{$\begin{array}{c}\text { Desahgar } \\
\text { s. }\end{array}$} & \multicolumn{15}{|c|}{$\mathrm{F}=2,38 \quad$ * $\mathrm{P}=\mathbf{0 , 0 5 2 2}$} \\
\hline & \multicolumn{3}{|c|}{ C.U } & \multicolumn{3}{|c|}{ T.U- C.E.U } & \multicolumn{3}{|c|}{ T.E.U } & \multicolumn{3}{|c|}{ ASOC. } & \multicolumn{3}{|c|}{ AYUD. } \\
\hline & $\begin{array}{c}\text { Medi } \\
\text { a }\end{array}$ & Sx & $\mathrm{Se}$ & $\begin{array}{c}\text { Medi } \\
\text { a }\end{array}$ & Sx & Se & $\begin{array}{c}\text { Medi } \\
\text { a }\end{array}$ & Sx & Se & $\begin{array}{c}\text { Medi } \\
\text { a }\end{array}$ & Sx & $\mathrm{Se}$ & $\begin{array}{c}\text { Medi } \\
\text { a }\end{array}$ & Sx & $\mathrm{Se}$ \\
\hline & 7,36 & $\begin{array}{c}2,1 \\
9\end{array}$ & $\begin{array}{c}0,4 \\
3\end{array}$ & 8,31 & 2,8 & $\begin{array}{c}0,3 \\
1\end{array}$ & 8,55 & $\begin{array}{c}3,1 \\
1\end{array}$ & $\begin{array}{c}{[0,4} \\
2\end{array}$ & 7,36 & $\begin{array}{c}2,6 \\
2\end{array}$ & $\begin{array}{c}0,2 \\
8\end{array}$ & 8,63 & $\begin{array}{c}3,2 \\
9\end{array}$ & $\begin{array}{c}0,9 \\
9\end{array}$ \\
\hline
\end{tabular}

Tabla 3. Resultados ANOVA Categorías docente/Modos de afrontamiento

* Diferencias estadísticamente significativas

- Tendencia a la significación 


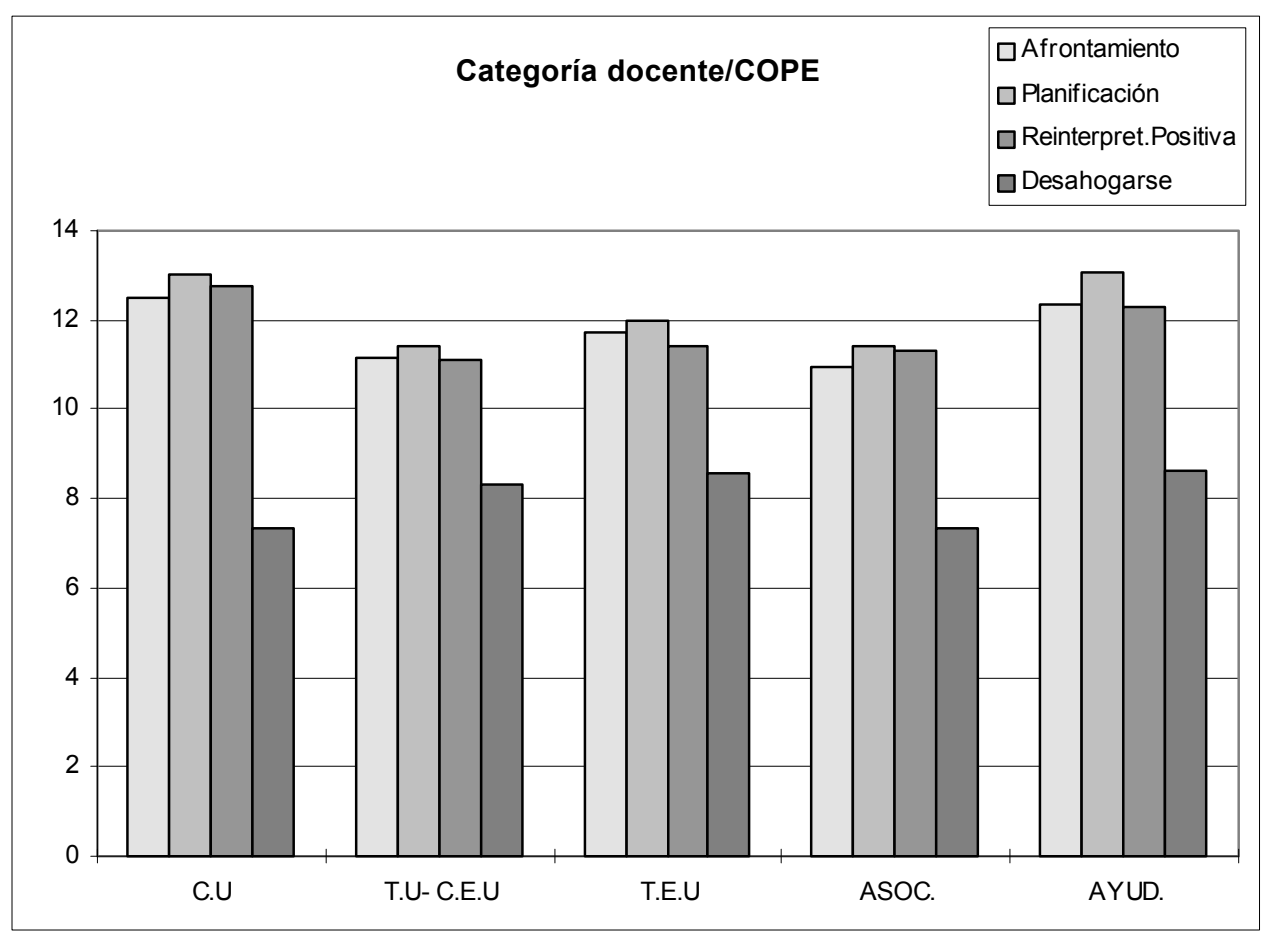

Gráfico 7. Valores medios Categorías docente/Modos de afrontamiento

- Tienden a un mayor absentismo por razones de salud, el profesorado que atribuye a los factores "sueldo" $(55,81 \%)$ y "masificación" (44\%), las principales fuentes de insatisfacción en su profesión.

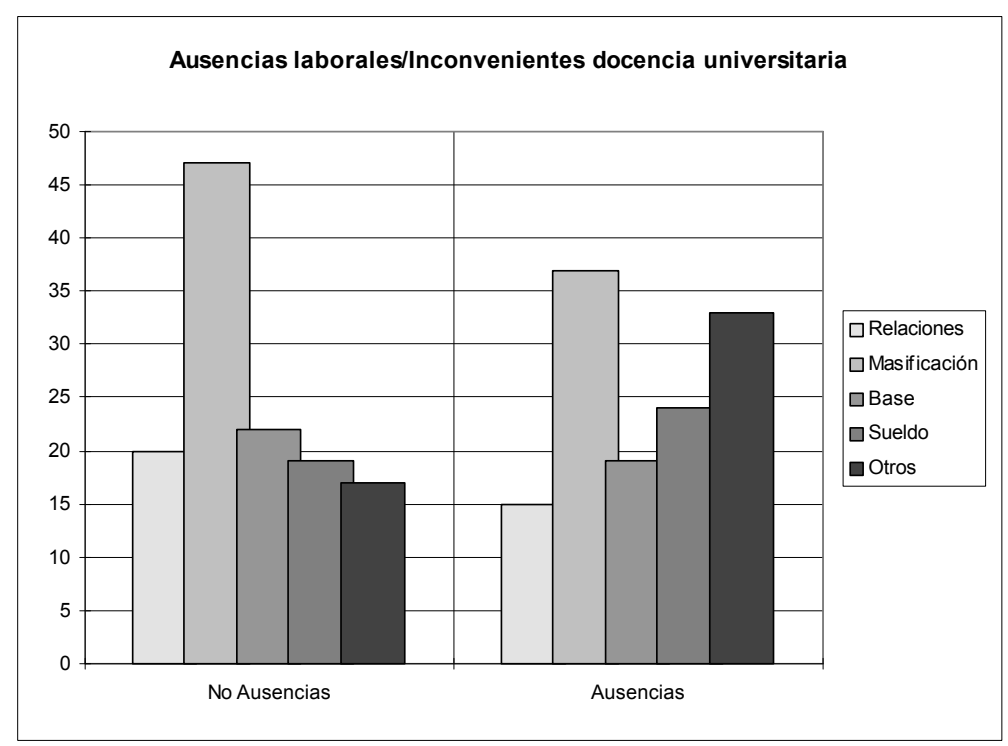

Gráfico 8. Distribución de frecuencias Ausencias/Inconvenientes

- También, absentismo por razones de salud se relaciona significativamente con Despersonalización ( $\mathrm{t}=-2,50 ; \mathrm{p}=0,0013)$.

- El profesorado que atribuye al factor "relaciones interpersonales" en el ámbito universitario la principal fuente de insatisfacción en su profesión, sufre mayor Agotamiento 
emocional. En cambio, el profesorado que lo atribuye a la "masificación" de las aulas sufre un menor Agotamiento emocional ( $F=2,37 ; p=0,0234)$.

- Cuando se contrasta Alicientes del trabajo docente universitario y la Escala de evaluación de técnicas de afrontamiento (1989), se observan diferencias altamente significativas en: Negación $(F=3,01 ; p=0,0189)$ y Desconexión Conductual $(F=4,20 ; p=0,026)$. Destacamos también la proximidad en: Religión ( $F=2,18 ; p=0,0717)$ y Reinterpretación Positiva $(F=1,97$; $p=0,0987)$

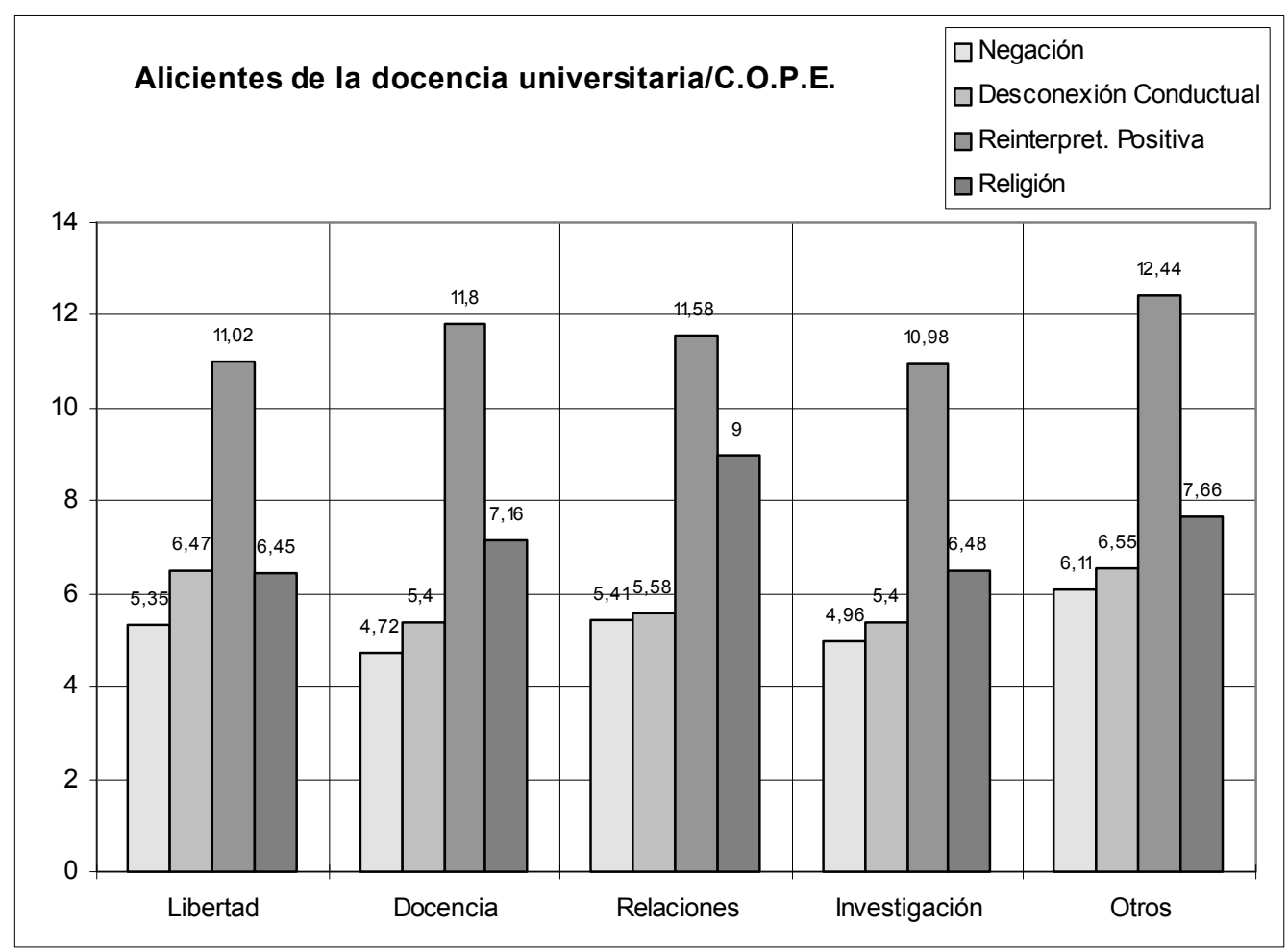

Gráfico 9. Valores medios Alicientes de la docencia universitaria/Modos de Afrontamiento

Específicamente, la prueba a posteriori PLSD de Fisher detectó significación en la subescala Negación en las comparaciones: Libertad vs. Docencia $(F=0,48)$, Docencia vs. Otros $(F=1,09)$ e Investigación vs. Otros $(F=1,13)$. La misma prueba determinó relación significativa en Desconexión Conductual en las comparaciones: Libertad vs. Relaciones ( $F=1,88)$, Docencia vs. Relaciones $(\mathrm{F}=1,81)$ y Relaciones vs. Investigación $(\mathrm{F}=1,95)$. 


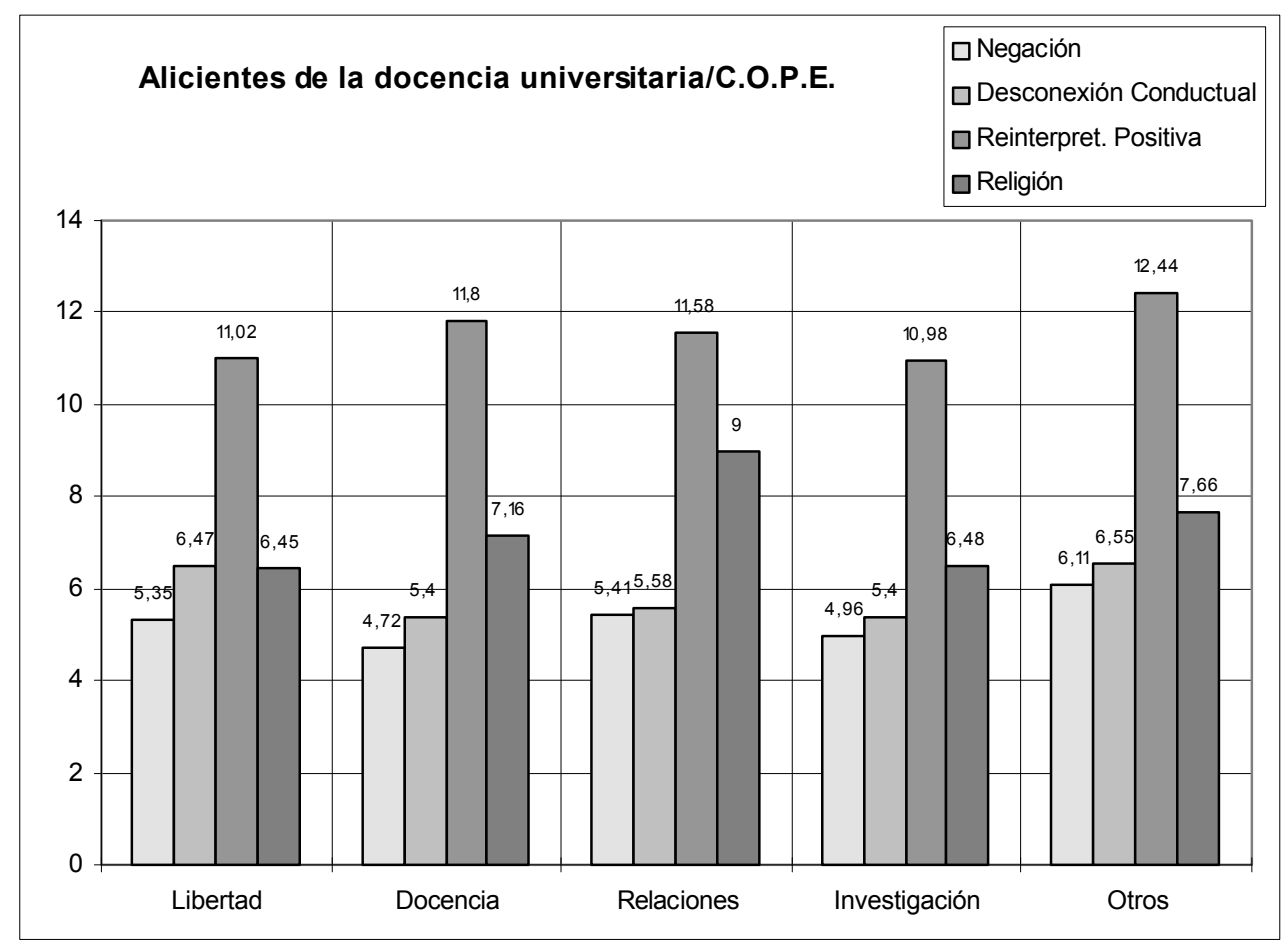

Gráfico 10. Valores medios Alicientes /Modos de Afrontamiento

El profesorado que emplean la estrategia Religión como modo de afrontar el estrés, también otorga a las Relaciones que se establecen en el trabajo un mayor valor. La subescala Reinterpretación Positiva registra los mayores promedios en el grupo que atribuyen a la Docencia la principal fuente de satisfacción en su trabajo

Finalmente, constatamos que percibir la "docencia" como fuente de satisfacción en la profesión universitaria puede modular, amortiguar y prevenir las ausencias al puesto de trabajo por razones de salud (Ji-cuadrado $=25,772 ; p=0,0573$ ).

\section{CONSIDERACIONES FINALES: PROPUESTA DE INTERVENCIÓN}

Con los datos que hemos presentando en este trabajo, los resultados y las conclusiones obtenidas, corroboramos que en el síndrome de Burnout están implicados factores que van desde los personales, el contexto de trabajo y la organización, pasando seguramente, por aquellos que están relacionados con la formación profesional. En cuanto a la relación entre afrontamiento del estrés y Burnout confirmamos que el empleo de las estrategias de control o centradas en el problema previene el desarrollo del síndrome y que el empleo de estrategias de evitación, de escape y centradas en la emoción facilita su aparición.

Creemos en la capacidad de autogestión humana, en las riquezas del intercambio, en la comunicación, así como en la utilidad del entrenamiento para manejar situaciones estresantes. Por ello, para concluir proponemos sencillas y útiles estrategias de intervención para el control y afrontamiento del Burnout, enfocadas tanto hacia la institución como al propio individuo. 
Proponemos dos tipos de programas de intervención: individuales y organizacionales. También de la literatura revisada hemos incluido un espacio que versa sobre las condiciones que modulan el estrés y su afrontamiento, bien facilitándolo o dificultándolo.

Dividimos en dos los programas y técnicas individuales:

a) Programas dirigidos a adquisición estrategias instrumentales cuyo contenido comprende el entrenamiento en solución de problemas, en habilidades de comunicación en general y de modo específico, intervención para hablar en público, entrenamiento en habilidades sociales (asertividad) y en el manejo del tiempo.

b) Programas dirigidos a manejar emociones, que constan del entrenamiento en la expresión de emociones, en el manejo de sentimientos de culpa y el entrenamiento en técnicas de relajación.

En los programas individuales creemos conveniente se incluyan también técnicas cognitivas y autocontrol y actividades tales como aumentar la competencia profesional y distanciamiento mental fuera de horario laboral.

Conocer las condiciones ambientales, conductuales, fisiológicas y cognitivas que catalizan el estrés y su afrontamiento, ayuda a prevenir los efectos nocivos y que pudieran derivar en Burnout. Estas condiciones son el apoyo social, la exposición a situaciones de carácter positivo, los recursos utilitarios, las condiciones fisiológicas y en general el estado de salud del sujeto. También, los modos de evaluación que emplea ante la situación estresante y la sensación de control. Insistimos en que existe evidencia empírica suficiente que asevera que una actitud optimista ayuda y actúa amortiguando el estrés.

Finalmente, aportamos algunas propuestas de intervención universitaria, a través de varios programas organizacionales, cuyo objetivo final ha de ser mejorar las condiciones y el clima laboral. Incluirían programas para el control de estrés, programas de formación inicial y permanente del profesorado y la intervención sobre aspectos organizativos y psicopedagógicos.

Todas las propuestas que se han señalado se han de insertar dentro de una planificación estratégica mucho más amplia que involucre la toma de conciencia del problema por parte del profesorado, el deseo y la responsabilidad de hacer algo al respecto.

Proponemos extender esta investigación a otras universidades nacionales e internacionales, deseando que se efectúen estudios comparativos e interprofesionales. La mayoría de las investigaciones sobre el síndrome se han centrado en la docencia. Existe otro personal de la docencia que ayuda, coordina o gestiona tareas afines y que prestan otros servicios. Nos referimos a directores de departamentos, vicerrectores y cargos directivos, sobre los que no se han realizado estudios sobre el desgaste que experimentan. Tampoco existen estudios de profesionales cercanos a la docencia, pero centrados en la investigación, tales como los becarios de investigación.

Son inexistentes los estudios longitudinales y de seguimiento, ya que en general se evalúa al profesional una sola vez, en una muestra única. Los estudios longitudinales nos proporcionarían una información muy valiosa sobre el proceso de desarrollo y las sucesivas 
fases sintomatológicas del síndrome, al mismo tiempo que nos permitiría conocer las relaciones causales entre los diferentes factores personales, sociales y laborales con los que se encuentra vinculado.

La necesidad de estudiar el síndrome viene unida a la necesidad de estudiar los procesos de estrés laboral, así como a enfatizar en la sensibilidad que las organizaciones han de poner en la calidad de vida laboral que ofrecen a sus empleados. Con frecuencia, los cambios, la calidad y la mejora que se piden al sistema educativo en general se realizan en medio de una falta lamentable de recursos materiales, formales y personales para llevarlos a cabo. En esta situación, es fácil asegurar que el síndrome de quemarse por el trabajo haga acto de presencia.

Gil-Monte y Peiró (1997) han señalado que resulta útil considerar los aspectos de bienestar y salud en el trabajo a la hora de evaluar la eficacia de una determinada organización, pues la calidad de vida laboral y el estado de salud física y psíquica que conlleva tiene repercusiones sobre la organización (absentismo, rotación, abandonos, disminución en la calidad, etc.). Asimismo, y dado que la mayor incidencia de Burnout se manifiesta en profesionales que prestan una función asistencial o social, el desgaste de la calidad de vida laboral va a conllevar repercusiones sobre la sociedad en general. Por nuestra parte, creemos con firmeza, haber contribuido al estudio, al conocimiento y a la identificación del síndrome para prevenirlo, afrontarlo de manera efectiva, así como paliar sus efectos sobre los profesionales de la enseñanza universitaria, los alumnos y sobre la propia institución. $Y$ concluimos recordando que, en palabras de Iwanicki (1983): " El síndrome de Burnout es una empresa colectiva y su comprensión, facilita el desarrollo de estrategias cooperativas más efectivas para aliviar el problema" 


\section{BIBLIOGRAFIA}

ALVAREZ, E.Y FDEZ, L. (1991): "El síndrome de "Burnout" o el desgaste profesional (I): revisión de estudios". En Revista Asociación Española Neuropsiquiatría, Vol.XI, n³9, p.257-265.

CARVER, C. S.; SCHEIER, M.F. Y WEINTRAUB, J. K. (1989): Assessing coping strategies: A theoretically based approach. Journal of Personality ang Social Psychology, 53, 267283.

CHERNISS, C. (1980): Professional Burnout in Human Service Organizations. En Moreno, B. y col. (1992). Configuración específica de estrés asistencial en profesores de BUP. Memoria de Investigación. CIDE.

CHERNISS, C. (1992): Long-term conseqyuences of burnout: an exploratory study. Manassero, M. A. y col. (1994). Burnout en profesores: impacto sobre la calidad de la educación, la salud y consecuencias para el desarrllo profesional. Memoria final de investigación. Madrid, MEC-CIDE.

COOX, T.; KUK, G. Y LEITER, M (1993): Burnout, health, work stress, and organizational healthiness. En Gil- Monte, P. y Peiró, J.M. (1997). Desgaste psíquico en el trabajo. Madrid. Síntesis Psicología.

EDELWICH, J. Y BRODSKY, A. (1980) Burnout: Stages of disillsionment in the helping professions. En Manassero, M. A. y col. (1994). Burnout en profesores: impacto sobre la calidad de la educación, la salud y consecuencias para el desarrllo profesional. Memoria final de investigación. Madrid, MEC-CIDE.

FARBER, B.A. (1985): Stress and burnout in the human service professions. Elmsford, New York: Pergamon Press.

FARBER, B. A. (1991): Crisis in education. Stress and Burnout in the american teacher. En Manassero, M. A. y col. (1994). Burnout en profesores: impacto sobre la calidad de la educación, la salud y consecuencias para el desarrollo profesional. Memoria final de investigación. Madrid. MEC-CIDE.

FISCHER, H. J. (1983): A psychoanalytic view of burnout. En Gil- Monte, P. y Peiró, J.M. (1997). Desgaste psíquico en el trabajo. Madrid: Síntesis Psicología.

FREUDENBERG, H. (1974): Saff burn-out. Journal of social issues. 30, 159-166.

GUERRERO, E. (1998): "Burnout" o desgaste psíquico y afrontamiento del estrés en el profesorado universitario. Tesis doctoral no publicada. Facultad de Educación. Universidad de Extremadura.

GIL-MONTE, P. Y PEIRÓ, J.M. (1997): Desgaste psíquico en el trabajo. Madrid: Síntesis Psicología.

GOLEMBIEWSKI, R.T.; MUNZENRIDER, R.F. Y STEVENSON , J.G. (1986): Stress in organizations: Toward a phase model of burnout. En Moreno, B. y col. (1992): Configuración específica de estrés asistencial en profesores de BUP. Memoria de Investigación. CIDE.

GOLEMBIEWSKI, R.T.Y MUNZENRIDER, R. F.Y CARTER (1983): Phases of progressive burnoutand theier work site covariants. En Gil- Monte, P. y Peiró, J.M. (1997): Desgaste psíquico en el trabajo. Madrid. Síntesis Psicología.

HARRISON, W.D. (1980): Role strain and burnout in child - protective service workers". En Moreno, B. y col. (1992). Configuración especifica de estrés asistencial en profesores de BUP. Memoria de Investigación. CIDE.

HARRISON, W.D. (1983): A social competence model of burnout. En Farber, B.A. (1985). Stress and burnout in the human service professions. Elmsford, New York: Pergamon Press.

IWANICKI, E.F. (1983): Toward understanding and alleviating teacher burnout. Theory into Practice, Vo. 22 (1) 27-32.

LEITER, M.P. Y MASLACH, C. (1988): The impact of interpersonal environment on burnout and organozational commitment. Journal of Organizational Behavior. 9 (4) 297-308.

MANASSERO, M. A.; VÁZQUEZ, A.; FERRER, M.V.; FORNÉS, J. Y FERNÁNDEZ, M.C. (1994): Burnout en profesores: impacto sobre la calidad de la educación, la salud y consecuencias para el desarrllo profesional. Memoria final de investigación. Madrid, MEC-CIDE.

MASLACH, C. (1982): Understanding burnout: Definitional issues in analyzing a complex phenomenon. In WS Paine (Ed): Job stress and burnout. Beverly Hills CA: Sage. 
MASLACH, C. Y JACKSON (1981): The measurement of experienced Burnout. Journal of occupational behavior. 2, 99-113.

MASLACH, C. Y JACKSON, S.E. (1985): Burnout research in the social services: a critique. Special issues: Burnout among social workers. Journal of social service research. 10 (1) 95-105.

MASLACH, C. Y JACKSON, S.E. (1986): Maslach Burnout Inventory. Manual research Edition. University of California. Consulting Psychologist Press. Palo Alto, C.A., 19.

P.S.I.S.A. (1993): El Burnout o desgaste profesional: Estudio Empírico de los profesionales de Educación Secundaria y Bachillerato en Salamanca. Beca financiada por Caja de Ahorros de Salamanca y Soria. Fondo Cultural Castilla y León. Salamanca

MASLACH, C Y PINES A. (1977): The burnout syndrome in day care setting. Child care quarterly. 62: 100-113.

PINES, A. Y ARONSON, E. (1988): Career Burnout. Causes and cures. En Manassero, M. A. y col. (1994): Burnout en profesores: impacto sobre la calidad de la educación, la salud y consecuencias para el desarrllo profesional. Memoria final de investigación. Madrid, MEC-CIDE.

PRICE, D. M. Y MURPHY, P. A. (1984): Staff burnout in the perspective of grief theory. En GilMonte, P. y Peiró, J.M. (1997): Desgaste psíquico en el trabajo. Madrid: Síntesis.

SPANOIL, L. Y CAPUTO, G. (1979): Professional burnout: A personal survival kit. Levington, MA: Human Services Associates.

STARNAMAN, S. M. Y MILLER, K. (1992): A test of a causal model of communication and Burnout in the teaching profession. En Manassero, M. A. y col. (1994): Burnout en profesores: impacto sobre la calidad de la educación, la salud y consecuencias para el desarrllo profesional. Memoria final de investigación. Madrid, MEC-CIDE.

WINNUBST, J.A. (1993): Organizational structure, social support, and burnout. En Gil-Monte, P. y Peiró, J.M. (1997): Desgaste psíquico en el trabajo. Madrid. Síntesis Psicología. 